\title{
UTILIZAÇÃO DE UM PLANEJAMENTO COMPOSTO CENTRAL PARA A OBTENÇÃO DAS MELHORES CONDIÇÕES DE TEMPERATURA, pH E CONCENTRAÇÃO DE GLICOSE PARA A PRODUÇÃO DE ETANOL UTILIZANDO A LEVEDURA Pachysolen tannophilus.
}

\author{
A. F. KLAFKE, A. V. MORCELLI, M. A. Z. AYUB
}

Universidade Federal do Rio Grande do Sul, Departamento de Engenharia Química E-mail para contato: andrefk@enq.ufrgs.br

\begin{abstract}
RESUMO - Neste trabalho foram estudadas a dinâmica de crescimento e a produção de etanol a partir de glicose pela levedura Pachysolen tannophilus ATCC-32691. A velocidade de crescimento celular máxima $\left(\mu_{\text {máx }}\right)$ foi calculada através da curva de crescimento e equivale a $0,34 \mathrm{~h}^{-1}$. Cultivos foram realizados em diferentes condições de temperatura, $\mathrm{pH}$ e concentração de glicose com o objetivo de se obter a melhor condição para a conversão da glicose a etanol através de um planejamento composto central. Obteve-se um modelo quadrático para a conversão de glicose a etanol, o qual foi validado por experimento em triplicata nas condições ótimas obtidas de $33,6^{\circ} \mathrm{C}, \mathrm{pH}$ igual a 4,37 e concentração de glicose igual a $42,3 \mathrm{~g} \cdot \mathrm{L}^{-1}$, que geraram um $\mathrm{Y}_{\mathrm{Etanol}}=0,47 \mathrm{~g} \cdot \mathrm{g}^{-1}$.
\end{abstract}

\section{INTRODUÇÃO}

Bioetanol é considerado o combustível alternativo renovável com o maior potencial para substituir combustíveis fósseis, com uma produção mundial de mais de 100 milhões de $\mathrm{m}^{3}$ em 2012 (Renewable Fuels Association, 2013a), e com um potencial para uma significativa redução de emissões de gases do efeito de estufa (Dias et al., 2013).

A levedura Pachysolen tannophilus pode fermentar alguns açúcares a etanol, sendo a primeira levedura identificada que tem uma capacidade significativa de converter xilose em etanol (Slininger et al., 1982; Schneider et al., 1981).

Neste trabalho foram estudadas a dinâmica de crescimento celular e de formação de metabólitos da levedura $P$. tannophilus, sendo realizado planejamento composto central a fim de avaliar as condições ótimas de temperatura, $\mathrm{pH}$ e concentração de glicose para a fermentação de glicose a etanol, sob condição de microaerofilia em escala de frasco.

\section{MATERIAS E MÉTODOS}

\subsection{Manutenção do microrganismo e preparo de inóculo}

O microrganismo utilizado nessa pesquisa foi a P. tannophilus ATCC-32691. Estoques dessa levedura são mantidos na Coleção de Culturas Microbiológicas do Bioteclab (UFRGS, 
Brasil). As culturas foram mantidas em tubos de Eppendorf contendo meio YMA (composto por $3 \mathrm{~g} \cdot \mathrm{L}^{-1}$ de extrato de levedura, $3 \mathrm{~g} \cdot \mathrm{L}^{-1}$ de extrato de malte, $5 \mathrm{~g} \cdot \mathrm{L}^{-1}$ de peptona bacteriológica e $10 \mathrm{~g} \cdot \mathrm{L}^{-1}$ de glicose), estocadas a $-80^{\circ} \mathrm{C}$, com subculturas sendo feitas em placas de Petri. Os pré-inóculos foram preparados retirando alçadas de células das placas de Petri, transferindo-as a frascos de Erlenmeyer de $500 \mathrm{~mL}$ com $200 \mathrm{~mL}$ de meio YPD, permitindo crescimento em incubadoras de agitação orbital a $200 \mathrm{rpm}$ e $30^{\circ} \mathrm{C}$ por $12 \mathrm{~h}$ (overnight). Os inóculos foram preparados a partir da transferência de $5 \mathrm{~mL}$ dos pre-inóculos para novos frascos de Erlenmeyer de $500 \mathrm{~mL}$ com $200 \mathrm{~mL}$ de meio YPD, incubando-os a 200 rpm e $30^{\circ} \mathrm{C}$ até que os inóculos atingissem a densidade ótica (DO) alvo de 1,0 lida a $\lambda=600$ $\mathrm{nm}$. Este procedimento foi utilizado como padrão para o inóculo de todos os experimentos.

\subsection{Planejamento de experimentos}

Um delineamento composto central (DOE) de três variáveis foi realizado a fim de obter as condições ótimas para conversão de glicose a etanol. As variáveis e seus valores codificados e não-codificados são apresentadas na Tabela 1.

Tabela 1 - Variáveis testadas e seus níveis no planejamento composto central.

\begin{tabular}{ccccccc}
\hline Variáveis & Nome & \multicolumn{2}{l}{ Variáveis codificadas } \\
\cline { 3 - 6 } & & $-1,68$ & -1 & 0 & 1 & 1,68 \\
\cline { 3 - 6 } & & 23,6 & 27,0 & 32,0 & 37,0 & 40,4 \\
$\mathrm{X}_{1}$ & Temperatura $\left({ }^{\circ} \mathrm{C}\right)$ & 3,63 & 5,0 & 7,0 & 9,0 & 10,36 \\
$\mathrm{X}_{2}$ & $\mathrm{pH}$ & 6,36 & 20,0 & 40,0 & 60,0 & 73,63 \\
$\mathrm{X}_{3}$ & $\begin{array}{c}\text { Concentração de } \\
\text { glicose no meio de } \\
\text { cultivo (g/L) }\end{array}$ & & & & & \\
\hline
\end{tabular}

A Tabela 2 apresenta os 17 tratamentos obtidos para as três variáveis, cada uma a cinco níveis. O delineamento constituiu-se de oito pontos fatoriais, seis pontos axiais (dois pontos axiais no eixo da variável) e uma triplicata do ponto central. A equação polinomial de segunda-ordem para as variáveis é dada:

$$
Y=\beta_{0}+\sum \beta_{i} X_{i}+\sum \beta_{i j} X_{i} X_{j}+\sum \beta_{i i} X_{i}^{2}
$$

onde $\mathrm{Y}$ é a variável de resposta, $\beta_{0}$ a constante, $\beta_{\mathrm{i}}, \beta_{\mathrm{ii}}$ e $\beta_{\mathrm{ij}}$ são os coeficientes para o efeito linear, quadrático e de interação entre variáveis, respectivamente, e $\mathrm{X}_{\mathrm{i}}$ e $\mathrm{X}_{\mathrm{j}}$ o nível codificado das variáveis $x_{i}$ e $x_{j}$, respectivamente. A equação quadrática acima foi utilizada para plotar as superfícies de todas as variáveis.

\subsection{Métodos analíticos}

As amostras das culturas foram preparadas por centrifugação a $3000 \cdot \mathrm{g}$ durante $15 \mathrm{~min}$ para sedimentar as células, seguido por filtração utilizando filtros de membrana de acetato de

Tabela 2 - Delineamento experimental e resultados do Planejamento Composto Central. 


XI Congresso Brasileiro de Engenharia
Química em Iniciação Científica
Unicamp - Campinas - SP
19 a 22 de julho de 2015

celulose (tamanho do poro de $0,45 \mu \mathrm{m}$; Sartorius, Alemanha). A composição do sobrenadante das culturas foi analisada utilizando HPLC (Shimadzu Corp.). A fase estacionária e a fase móvel utilizadas foram uma coluna Aminex HPX-87H $(300 \times 7.8 \mathrm{~mm}$, Bio-Rad, USA) e uma solução $0,005 \mathrm{~mol} \cdot \mathrm{L}^{-1}$ de $\mathrm{H}_{2} \mathrm{SO}_{4}$, respectivamente. As condições utilizadas foram 0,8 $\mathrm{mL} \cdot \mathrm{min}^{-1}$ de vazão da fase móvel e $65^{\circ} \mathrm{C}$. A concentração de biomassa foi estimada através do método de peso seco. Todas as amostras recolhidas para análise das experiências foram realizadas em duplicata.

\section{RESULTADOS}

\subsection{Cinética de crescimento e formação de metabólitos}

Foram feitos experimentos de acompanhamento do crescimento de biomassa e produção de metabólitos pela levedura $P$. tannophilus, utilizando glicose como fonte de carbono. Os resultados deste acompanhamento são mostrados na Figura 1. Neste experimento observou-se uma produção de biomassa igual a $7,05 \mathrm{~g} \cdot \mathrm{L}^{-1}$ ao final de $24 \mathrm{~h}$ e uma concentração máxima de etanol de 8,53 $\mathrm{g} \cdot \mathrm{L}^{-1}$ após $16 \mathrm{~h}$ de cultivo. O consumo de glicose foi quase total ao final das $24 \mathrm{~h}$ de experimento. Em adição, houve produção de ácido acético e ácido lático, porém, em níveis baixos, com concentrações máximas de $0,72 \mathrm{~g} \cdot \mathrm{L}^{-1}$ e $0,82 \mathrm{~g} \cdot \mathrm{L}^{-1}$, respectivamente. A velocidade específica de crescimento máxima $\left(\mu_{\text {máx }}\right)$ foi calculada a partir dos dados da curva de crescimento e equivale a $0,34 \mathrm{~h}^{-1}\left(\mathrm{R}^{2}=0,998\right)$. 
Figura 1 - Cinética de crescimento de biomassa ( $\downarrow)$ e formação de glicose $(\boldsymbol{\square})$ e etanol $(\boldsymbol{\Delta})$ em escala de frasco

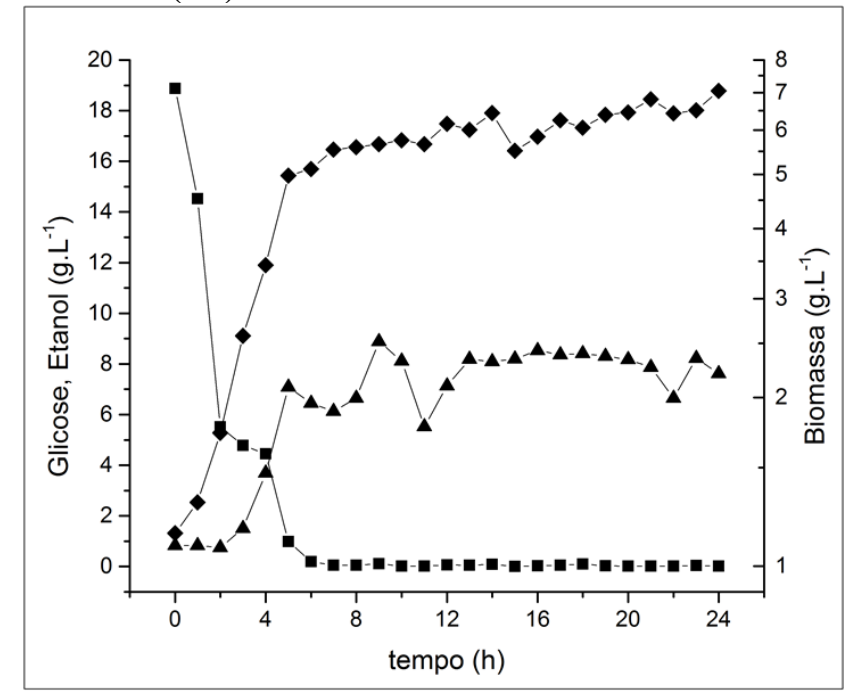

\subsection{Planejamento composto central}

A análise estatística dos dados obtidos no planejamento composto central (Tabela 2) levou à exclusão do efeito linear da temperatura $\left(\mathrm{X}_{1}\right)$ bem como os efeitos de interação entre temperatura e $\mathrm{pH}\left(\mathrm{X}_{1} \mathrm{X}_{2}\right)$ e entre $\mathrm{pH}$ e concentração de glicose $\left(\mathrm{X}_{2} \mathrm{X}_{3}\right)$, uma vez que apresentaram valor de $\mathrm{p}$ calculado consideravelmente superior ao intervalo de confiança de $10 \%$. A tabela ANOVA resultante é apresentada abaixo.

Segundo a Tabela 3, mostraram-se significativas as contribuições linear e quadrática da concentração de glicose e a contribuição linear do $\mathrm{pH}$. Dessa forma, obteve-se a equação representativa do modelo obtido para a conversão de glicose a etanol:

$$
\mathrm{Y}=0,484-0,068 * \mathrm{X}_{2}+0,039 * \mathrm{X}_{3}-0,049 * \mathrm{X}_{3}^{2}
$$

$\mathrm{O}$ modelo apresentou coeficiente de regressão múltipla $\mathrm{R}^{2}=0,7$ e sua significância foi comprovada pelo teste F-Fischer (Fcalculado $=3,77>$ Ftabelado $=3,21$ ). A Figura 2 apresenta superfície de resposta para uma temperatura fixada em $32{ }^{\circ} \mathrm{C}$.

Através do modelo quadrático foram obtidos os valores críticos de temperatura, $\mathrm{pH}$ e concentração de glicose exibidos na Tabela 4. Para tais valores, a conversão de glicose a etanol prevista pelo modelo é de 0,51 .

Validação do planejamento composto central: foi realizado um experimento de validação do modelo obtido de forma análoga aos demais experimentos, que constituiu-se de cultivo em triplicata do microrganismo testado nas condições ótimas obtidas pelo modelo quadrático. Observou-se uma média de conversão de glicose a etanol ( $\left.\mathrm{Y}_{\text {Etanol }}\right)$ de 0,47 , com desvio padrão de 0,015 . Em comparação ao valor previsto pelo modelo para tal variável nas condições ótimas, de $\mathrm{Y}_{\text {Etanol }}=0,51$, a diferença observada consiste em um erro de 7,98\%. Desta forma, considera-se o modelo satisfatório. 
Tabela 3 - Análise estatística do planejamento composto central realizado (avaliada a intervalo de confiança de $10 \%$ ).

\begin{tabular}{ccc}
\hline Variável & Efeito & $\mathrm{p}$ \\
\hline Efeitos Lineares & & \\
$\mathrm{X}_{2}$ & $-0,068$ & 0,007 \\
$\mathrm{X}_{3}$ & 0,039 & 0,087
\end{tabular}

Efeitos Quadráticos

$\begin{array}{lll}\mathrm{X}_{1} & -0,038 & 0,124 \\ \mathrm{X}_{2} & -0,028 & 0,245 \\ \mathrm{X}_{3} & -0,049 & 0,051\end{array}$

Interações

$\mathrm{X}_{1} \mathrm{X}_{3} \quad-0,036 \quad 0,212$

Tabela 4 - Valores críticos do modelo quadrático obtido (resposta prevista, $\mathrm{Y}_{\text {Etanol }}=0,51$ )

\begin{tabular}{ccc}
\hline Variável & Valor codificado & Valor Real \\
\hline Temperatura & 0,325 & 33,6 \\
$\mathrm{pH}$ & $-1,315$ & 4,37 \\
Glicose (g.L-1) & 0,113 & 42,3 \\
\hline
\end{tabular}

triplicata do microrganismo testado nas condições ótimas obtidas pelo modelo quadrático. Observou-se uma média de conversão de glicose a etanol ( $\left.\mathrm{Y}_{\text {Etanol }}\right)$ de 0,47 , com desvio padrão de 0,015 . Em comparação ao valor previsto pelo modelo para tal variável nas condições ótimas, de $\mathrm{Y}_{\text {Etanol }}=0,51$, a diferença observada consiste em um erro de 7,98\%. Desta forma, considera-se o modelo satisfatório.

\section{CONCLUSÃO}

O acompanhamento da cinética de crescimento da levedura mostrou que a glicose consumida foi direcionada, principalmente, para crescimento celular e produção de etanol, e 


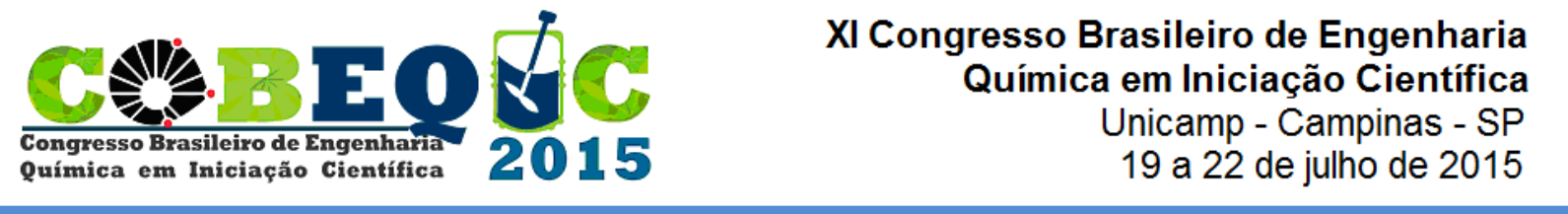

Figura 2 - Superfície de resposta para a conversão de glicose a etanol em função da variação de $\mathrm{pH}$ e da concentração de glicose a temperatura fixa de $32{ }^{\circ} \mathrm{C}$

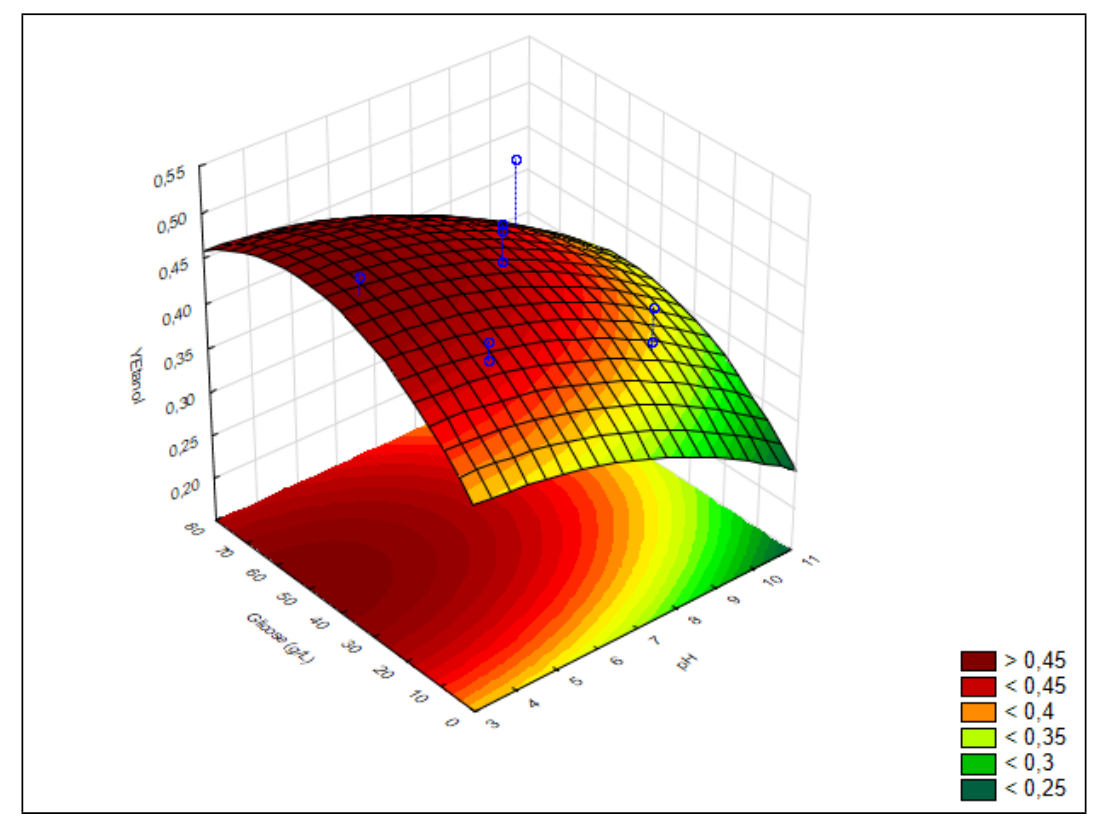

possibilitou o cálculo da velocidade específica de crescimento máxima $\left(\mu_{\operatorname{máx}}=0,34 \mathrm{~h}^{-1}\right)$. A partir do planejamento composto central foi possível obter um modelo para as condições ótimas para a conversão de glicose a etanol, sendo essas $33,6{ }^{\circ} \mathrm{C}, \mathrm{pH}$ igual a $4,37 \mathrm{e}$ concentração de glicose igual a $42,3 \mathrm{~g} \cdot \mathrm{L}^{-1}$. O modelo foi validado por experimento em triplicata, uma vez que apresentou erro inferior a 10\%. Assim, foi mostrado que a levedura $P$. tannophilus ATCC-32691 é capaz de fermentar glicose a etanol sob condições de microaerofilia de maneira eficiente e em condições brandas. A continuidade do presente estudo consiste no escalonamento de processo para o qual se sugere a condução de experimentos em escala de biorreator de bancada, a fim de avaliar os melhores parâmetros de aeração para reproduzir as condições de microaerofilia obtidas em escala de frasco. Observase potencial para aumento da conversão a etanol mediante a utilização de outros modos de operação, sobretudo o de batelada alimentada.

\section{REVISÃO BIBLIOGRÁFICA}

DIAS, M. O. S. et al. Evaluation of process configurations for second generation integrated with first generation bioethanol production from sugarcane. Fuel Processing Technology, v. 109, n. 0, p. 84-89, 2013.

RENEWABLE FUELS ASSOCIATION. World fuel ethanol production. Disponível em: $<$ http://ethanolrfa.org/pages/World-Fuel-Ethanol-Production>, acessado em 27/02/2015.

SCHNEIDER, H. et al. Conversion of D-xylose into ethanol by the yeast Pachysolen tannophilus. Biotechnology Letters, v. 3, n. 2, p. 89-92, 1981.

SLININGER, P. J. et al. Conversion of D-xylose to ethanol by the yeast Pachysolen tannophilus. Biotechnology and Bioengineering, v. 24, n. 2, p. 371-384, 1982. 